\title{
A Study on Multi-Enriched Housing Environment in Blue Foxes
}

\author{
Hannu T. Korhonen, Pekka Eskeli \\ Natural Resources Institute Finland (Luke), Silmäjärventie, Kannus, Finland \\ Email: hannu.t.korhonen@luke.fi
}

Received 9 February 2015; accepted 22 March 2015; published 27 March 2015

Copyright $@ 2015$ by authors and Scientific Research Publishing Inc.

This work is licensed under the Creative Commons Attribution International License (CC BY). http://creativecommons.org/licenses/by/4.0/

(c) ()

\begin{abstract}
A traditional fox cage was furnished with both activating environmental enrichments (EE) (a bone, a scratching plate, a hockey buck, a ceiling rope and a wall rope and straw) and EEs enabling resting or observation (a wire-mesh platform and a top nest box). The aim was to find out to which extent blue foxes (Vulpes lagopus) utilized these EEs, and to collect practical experiences of the EEs. The experimental animals were 12 adult blue fox vixens that had been housed in cages furnished with a platform and a bone for about 1.5 years before they were transferred to the multi-enriched cages. The frequency and duration of the active contacts with the EEs were measured with continuous recording on Days 1, 2, 7 and 16 after the transfer, with three hours $(13: 30$ - 14:30, 18:00 19:00 and 2:00 - 3:00) on each day. The total use of the EEs was 15 times per hour and more than $20 \%$ of the time. For most EEs both the time spent in contact and the frequency of contacts with the EEs declined steeply after Day 1, reflecting a novelty effect of the EEs. This decline was not so evident for the platform, top nest box and wall rope. These three EEs were also the ones used the most by the foxes. The ropes were badly damaged during the experiments, whereas other EEs remained in good condition. Explorativity markedly increased when animals were transferred from home cage to enriched cages. Explorativity remained high during entire study period when foxes were kept in enriched enrichment. Furthermore, it remained high also after transferring of animals back to home cages. Capture reaction was quite similar in home and enriched cages. The amount of stereotypy varied among recording days $(P<0.05)$. When foxes were transferred from home cages to multi-enriched cages, no change was found in the amount stereotypy during Days 1 and 2 . Thereafter, the amount of stereotypy showed a declined trend. Stereotypy tended to increase when foxes were transferred back to home cages. Our results indicated that foxes used readily the opportunities for more diverse behaviours.
\end{abstract}

\section{Keywords}

Vulpes lagopus, Animal Welfare, Behaviour, Environmental Enrichment 


\section{Introduction}

Environmental enrichment (EE) refers to environmental modifications to the housing environment of captivekept animals that enhance the performance of strongly motivated species-specific behaviours and/or lead to the expression of a more complex behavioural repertoire [1]. The ultimate aim of EE is to improve the physical and psychological welfare of animals [2].

Farmed blue foxes (Vulpes lagopus) are housed in wire-mesh cages under shed. The obligatory EEs in their cages are an elevated platform and suitable chewing material or other enrichment materials [3]. Typically, wooden blocks or bones are used for the latter purpose. The effects of the platforms [4] and chewing objects [5], as well as various other EE objects and materials, i.e. sand floor [6], scratching plate [7], and straw [8] on the welfare have been studied in various experimental set-ups. Usually the studies have focused on situations where there have been only one or a few EEs in a standard fox cage [5] [8]. If the foxes had had available several EEs simultaneously, the EEs would have been provided in large cage systems [4] [9]. However, several studies have shown recently that providing farmed mink with environmental complexity, i.e. several EEs provided simultaneously, in standard commercial cages improves the mink's welfare and reproductive performance [10]-[13].

In the present study, traditional farm fox cage was furnished with versatile enrichments. Here we present the results of a study aiming at designing a multi-enriched housing environment for blue foxes. EEs must be practical [14] [15], and therefore EEs in our study are suitable to the cage constructions used today on farms. Some of the EEs (a platform, nest box on the roof of the cage, bone, scratching plate and straw) have been studied earlier, but we introduce also new EE objects (a hockey buck, ceiling rope and wall rope). In the present paper we report the extent of the use of the EEs by adult female blue foxes, and also discuss the usability and durability of the EEs. Furthermore, foxes' behaviours were compared in their home cages and in multi-enriched environment. A crucial question here is "are obligatory enrichments in a traditional home cage sufficient to provide a proper behavioural pattern or should additional equipments be placed into the cage environment simultaneously?"

\section{Material and Methods}

\subsection{Experimental Set-Up and Animals}

This study was carried out at Turkistila Luova Ltd. in Kannus, western Finland $\left(63.54^{\circ} \mathrm{N} ; 23.54^{\circ}\right.$ E). Experimental animals were 12 adult female blue foxes. They were housed in their home cages about 1.5 years before the experiment. Behaviour of foxes was recorded in their home cages $(107 \mathrm{~cm} \times 115 \mathrm{~cm} \times 70 \mathrm{~cm}, \mathrm{~L} \times \mathrm{W} \times \mathrm{H})$ in $\mathrm{De}-$ cember 2012. Thereafter, animals were transferred from their home cages to multi-enriched cages of the same size on 27 December. The home cage was furnished with a wire-mesh platform $(105 \mathrm{~cm}$ long $\times 25 \mathrm{~cm}$ wide, located $23 \mathrm{~cm}$ from the roof of the cage) and a bone $(30 \mathrm{~cm}$ long $\times 7 \mathrm{~cm}$ diameter $)$. After 26 days, the experimental animals were transferred back to their home cages on January 2013.

Each multi-enriched cage had a similar platform and a bone as the home cage, but also five other EEs (Frondelius et al. 2013). A top nest box (wooden walls and ceiling, wire-mesh floor; $40 \mathrm{~cm}$ wide $\times 70 \mathrm{~cm}$ long $\times 40$ $\mathrm{cm}$ high) was situated on the roof of the cage, and the access to the box was via the platform. Additional enrichments were straw (placed between the walls of the neighbouring cages), a scratching plate (wooden, mounted against the wall; $45 \mathrm{~cm}$ wide $\times 45 \mathrm{~cm}$ high), a wall rope (sisal fiber, from cage to cage, enabled interaction between two neighbouring foxes; diameter $11 \mathrm{~mm}$ and length $30-40 \mathrm{~cm}$ ) and a ceiling rope (sisal fiber; hanging $30 \mathrm{~cm}$ from the ceiling, diameter $11 \mathrm{~mm}$ ), and a hockey puck (rubber: diameter $76 \mathrm{~mm}, 25 \mathrm{~mm}$ thick).

\subsection{Feeding and Health Evaluation}

Animals were fed once a day (at 10:30) with fresh fox feed manufactured by the local feed kitchen (Kalajoen jäähdyttämö Ltd.). Fresh water was available ad libitum from automatic watering devices. The use of experimental animals was evaluated and approved by the Animal Care Committee. The health of experimental animals was checked visually every day to ensure that the EEs were not hazardous to the animals. At the same time also the condition of the EEs was checked, and any destroyed EEs were replaced with new ones.

\subsection{Behaviour from Video Recordings}

The behaviour was monitored during the experiment [7] [8]. The video recording setup comprised of MIRASYS recorder (V5016HI), monitor (TFTR 17) and 12 cameras (WZI8 PV312-0). Animals were continuously video 
recorded during the study. The frequencies and durations of the active contacts with the EEs were analysed from video-recordings with continuous recording on Days 1, 2, 7 and 16 of the experiment, for three hours on each day (13:30 - 14:30, 18:00 - 19:00, and 2:00 - 3:00). Furthermore, Day $5(-5)$ before transferring from home cage to multi-enriched cage was recorded and analysed similarly. In addition, Day 30, i.e. 2 days since animals were transferred from multi-enriched cages back to home cages was recorded and analysed.

\subsection{Behavioural Tests}

Explorative behaviour was evaluated by a ball test in which a floor ball was placed in the cage. Contact to ball was recorded [16]. If there was no contact within 10 seconds, the test was aborted. Capture test was made before weighting of animals. Foxes were caught with neck tongs. Capture reaction was classified as confident or fearful [7].

\subsection{Statistics}

For the statistical analyses, the EEs were grouped to "resting EEs" (platform and top nest box) and "activity EEs" (the wall rope, ceiling rope, hockey buck, bone, scratching plate and straw). The analyses we carried out in two ways: by taking and by not taking into account this grouping. The differences between the use, i.e. durations expressed as \% of time and frequencies expressed as times per hour, of the various EEs and four observation days were analysed with non-parametric Friedman's and Wilcoxon's tests, since the assumptions of parametric statistics were not fulfilled [15] [17].

\section{Results}

\subsection{Condition Score of Enrichments}

The wall rope of each fox had to be replaced with a new rope at least once during the experimental period, because the rope was totally destroyed. Also most ceiling ropes were damaged, but mostly not to the extent that they should have been replaced with new ones (Table 1). All other EEs remained in good condition during the

Table 1. Number of foxes with condition score (good, fairly good, moderate, and poor) of wall ropes and ceiling ropes during the course of experiments.

\begin{tabular}{|c|c|c|c|c|c|}
\hline \multirow{2}{*}{ Day in multi-enriched cage } & \multicolumn{5}{|c|}{ Wall rope } \\
\hline & Good & Fairly good & Moderate & Poor & Changed \\
\hline 1 & 0 & 4 & 2 & 0 & 6 \\
\hline 2 & 0 & 0 & 4 & 0 & 8 \\
\hline 5 & 0 & 0 & 10 & 0 & 2 \\
\hline 7 & 0 & 0 & 8 & 0 & 4 \\
\hline 10 & 0 & 0 & 4 & 2 & 6 \\
\hline 13 & 0 & 0 & 1 & 2 & 9 \\
\hline 16 & 0 & 0 & 9 & 1 & 2 \\
\hline \multirow{2}{*}{ Day in multi-enriched cage } & \multicolumn{5}{|c|}{ Ceiling rope } \\
\hline & Good & Fairly good & Moderate & Poor & Changed \\
\hline 1 & 0 & 9 & 2 & 1 & 0 \\
\hline 2 & 0 & 7 & 5 & 0 & 0 \\
\hline 5 & 0 & 0 & 12 & 0 & 0 \\
\hline 7 & 0 & 0 & 11 & 1 & 0 \\
\hline 10 & 0 & 0 & 12 & 0 & 0 \\
\hline 13 & 0 & 0 & 10 & 2 & 0 \\
\hline 16 & 0 & 0 & 10 & 0 & 2 \\
\hline
\end{tabular}


experiment. No health problems were observed during the experiments.

\subsection{The Use of Enrichments}

The platform was visited more frequently than the top nest box, but there was no difference between the total percentages of time the foxes spent on or in, respectively, these activity enrichments (Table 2 and Table 3 ). The wall rope was the most favoured of the activity EEs, followed by the ceiling rope, the bone, the hockey buck, the scratching plate and straw.

In total, the foxes used the EEs on average for more than $20 \%$ of their time and had 15 contacts per hour with the EEs (Table 2 and Table 3). However, for most EEs both the time spent in contact and the frequency of contacts with the EEs declined steeply after Day 1 . This decline was absent for the duration of the contacts with the platform and top nest box, and not statistically significant $(\mathrm{P}>0.05)$ for the duration and frequency of the use of the wall rope.

Although the total number of contacts with the EEs dropped to less than one third after Day 1, the average number of active contacts with the EEs was still from eight to ten per hour on Days 2 - 16. The wall rope, ceiling rope and bone covered approximately $60 \%-70 \%$ of the contacts. The total duration of the contacts with the EEs dropped first to two thirds and then to one third from Day 1 to Days 2 and 7, respectively, but returned then on Day 16 to almost to the same level as on Day 1 (Table 2). The platform and top nest box accounted for $65 \%-90 \%$ of the total time spent on using the EEs, and the day-to-day fluctuations resulted mainly from to the fluctuations in the use of the top nest boxes.

Platform use varied with time $(\mathrm{P}<0.05)$. It was highest when foxes were in their home cages and lowest in multi-enriched cages (Figure 1). Use of bone was rather low in all dates except during the first day when foxes were transferred into the multi-enriched cages (Figure 1).

Table 2. The use of the various enrichments expressed as percentages of time. Statistics by Friedman's test (P1, P3, and P5) or Wilcoxon's test (P2, and P4): P1 = differences between the four days; P2 = differences between the two "resting enrichments"; P3 = differences between the six "activity enrichments"; P4 = differences between the "resting enrichments" and "activity enrichments"; P5 = differences between the eight enrichments.

\begin{tabular}{|c|c|c|c|c|c|c|c|}
\hline & \multirow{2}{*}{ Enrichment } & \multirow{2}{*}{ All days } & \multicolumn{4}{|c|}{ Day } & \multirow{2}{*}{$\mathrm{P} 1$} \\
\hline & & & 1 & 2 & 7 & 16 & \\
\hline \multirow{4}{*}{$\begin{array}{l}\text { "Resting } \\
\text { enrichments" }\end{array}$} & Platform & $8.5 \pm 12.3$ & $7.1 \pm 9.2$ & $11.7 \pm 25.7$ & $6.1 \pm 9.7$ & $9.1 \pm 18.7$ & NS \\
\hline & Top nest box & $7.7 \pm 9.2$ & $11.5 \pm 20.1$ & $5.7 \pm 12.9$ & $0.7 \pm 2.2$ & $12.9 \pm 24.4$ & NS \\
\hline & $\begin{array}{l}\text { Total for resting } \\
\text { enrichments }\end{array}$ & $16.2 \pm 16.0$ & $18.7 \pm 19.2$ & $17.4 \pm 33.1$ & $6.8 \pm 11.0$ & $22.1 \pm 31.4$ & NS \\
\hline & $\mathrm{P} 2$ & NS & NS & NS & $<0.01$ & NS & \\
\hline \multirow{11}{*}{$\begin{array}{l}\text { "Activity } \\
\text { enrichments" }\end{array}$} & Bone & $0.5 \pm 0.6$ & $1.1 \pm 1.7$ & $0.2 \pm 0.3$ & $0.4 \pm 0.9$ & $0.4 \pm 0.7$ & $<0.01$ \\
\hline & Hockey puck & $0.4 \pm 0.4$ & $1.1 \pm 1.1$ & $0.1 \pm 0.3$ & $0.3 \pm 0.9$ & $0.1 \pm 0.2$ & $<0.01$ \\
\hline & Ceiling rope & $1.2 \pm 1.2$ & $4.0 \pm 5.2$ & $0.2 \pm 0.5$ & $0.4 \pm 0.7$ & $0.2 \pm 0.4$ & $<0.01$ \\
\hline & Wall rope & $2.2 \pm 1.4$ & $3.6 \pm 3.4$ & $1.1 \pm 1.8$ & $2.0 \pm 3.4$ & $2.0 \pm 3.6$ & $<0.1$ \\
\hline & Straw & $0.2 \pm 0.2$ & $0.5 \pm 0.4$ & $0.2 \pm 0.4$ & $0.03 \pm 0.04$ & $0.1 \pm 0.1$ & $<0.05$ \\
\hline & Scratching plate & $0.2 \pm 0.1$ & $0.4 \pm 0.4$ & $0.1 \pm 0.1$ & $0.1 \pm 0.1$ & $0.2 \pm 0.4$ & $<0.01$ \\
\hline & $\begin{array}{c}\text { Total for activity } \\
\text { enrichment }\end{array}$ & $4.7 \pm 2.6$ & $10.8 \pm 6.8$ & $1.9 \pm 2.1$ & $3.2 \pm 4.1$ & $2.9 \pm 3.6$ & $<0.001$ \\
\hline & P3 & $<0.001$ & $<0.01$ & $<0.1$ & $<0.01$ & NS & \\
\hline & $\begin{array}{l}\text { Total for all } \\
\text { enrichments }\end{array}$ & $20.9 \pm 16.8$ & $29.4 \pm 19.3$ & $19.3 \pm 33.0$ & $10.0 \pm 11.9$ & $25.0 \pm 33.5$ & $<0.05$ \\
\hline & $\mathrm{P} 4$ & $\mathrm{P}<0.1$ & NS & NS & $\mathrm{NS}$ & NS & \\
\hline & P5 & $\mathrm{P}<0.001$ & $\mathrm{P}<0.001$ & $\mathrm{P}<0.1$ & $\mathrm{P}<0.001$ & NS & \\
\hline
\end{tabular}


Table 3. The use of the various enrichments expressed as frequencies per hour. Statistics by Friedman's test (P1, P3, and P5) or Wilcoxon's test (P2, and P4): P1 = differences between the four days; P2 = differences between the two "resting enrichments"; P3 = differences between the six "activity enrichments"; P4 = differences between the "resting enrichments" and "activity enrichments"; P5 = differences between the eight enrichments.

\begin{tabular}{|c|c|c|c|c|c|c|c|}
\hline & \multirow{2}{*}{ Enrichment } & \multirow{2}{*}{ All days } & \multicolumn{4}{|c|}{ Day } & \multirow{2}{*}{$\mathrm{P} 1$} \\
\hline & & & 1 & 2 & 7 & 16 & \\
\hline \multirow{4}{*}{$\begin{array}{l}\text { "Resting } \\
\text { enrichments" }\end{array}$} & Platform & $2.0 \pm 1.2$ & $3.9 \pm 3.1$ & $0.9 \pm 1.4$ & $2.3 \pm 1.5$ & $0.8 \pm 0.7$ & $<0.01$ \\
\hline & Top nest box & $0.4 \pm 0.3$ & $1.0 \pm 1.1$ & $0.2 \pm 0.3$ & $0.1 \pm 0.1$ & $0.2 \pm 0.4$ & $<0.01$ \\
\hline & $\begin{array}{l}\text { Total for resting } \\
\text { enrichments }\end{array}$ & $2.3 \pm 1.4$ & $4.9 \pm 4.0$ & $1.1 \pm 1.6$ & $2.3 \pm 1.4$ & $1.0 \pm 0.9$ & $<0.01$ \\
\hline & $\mathrm{P} 2$ & $<0.01$ & $<0.01$ & $<0.05$ & $<0.01$ & $<0.05$ & \\
\hline \multirow{11}{*}{$\begin{array}{l}\text { "Activity } \\
\text { enrichments" }\end{array}$} & Bone & $2.5 \pm 1.2$ & $4.6 \pm 2.5$ & $1.3 \pm 2.1$ & $1.4 \pm 1.4$ & $2.6 \pm 2.8$ & $<0.01$ \\
\hline & Hockey puck & $1.3 \pm 0.8$ & $3.4 \pm 2.2$ & $0.5 \pm 0.5$ & $0.8 \pm 0.8$ & $0.5 \pm 0.9$ & $<0.001$ \\
\hline & Ceiling rope & $2.8 \pm 1.8$ & $7.7 \pm 7.8$ & $1.1 \pm 1.8$ & $1.5 \pm 2.2$ & $0.9 \pm 1.4$ & $<0.01$ \\
\hline & Wall rope & $4.2 \pm 1.5$ & $7.1 \pm 5.6$ & $3.1 \pm 3.3$ & $3.0 \pm 4.0$ & $3.7 \pm 4.3$ & NS \\
\hline & Straw & $0.8 \pm 0.6$ & $1.9 \pm 1.5$ & $0.6 \pm 1.2$ & $0.2 \pm 0.4$ & $0.5 \pm 0.5$ & $<0.01$ \\
\hline & Scratching plate & $1.1 \pm 0.9$ & $1.9 \pm 1.6$ & $0.7 \pm 1.1$ & $0.6 \pm 0.7$ & $1.1 \pm 2.1$ & $<0.05$ \\
\hline & $\begin{array}{l}\text { Total for activity } \\
\text { enrichments }\end{array}$ & $12.7 \pm 3.9$ & $26.7 \pm 12.2$ & $7.3 \pm 7.4$ & $7.4 \pm 6.6$ & $9.2 \pm 6.6$ & $<0.01$ \\
\hline & P3 & $<0.001$ & $<0.001$ & $<0.01$ & $<0.01$ & $<0.01$ & \\
\hline & $\begin{array}{l}\text { Total for all } \\
\text { enrichments }\end{array}$ & $15.0 \pm 5.1$ & $31.6 \pm 15.1$ & $8.3 \pm 8.9$ & $9.7 \pm 7.0$ & $10.2 \pm 7.0$ & $<0.001$ \\
\hline & P4 & $<0.01$ & $<0.01$ & $<0.01$ & $<0.05$ & $<0.01$ & \\
\hline & P5 & $<0.001$ & $<0.001$ & $<0.01$ & $<0.001$ & $<0.01$ & \\
\hline
\end{tabular}
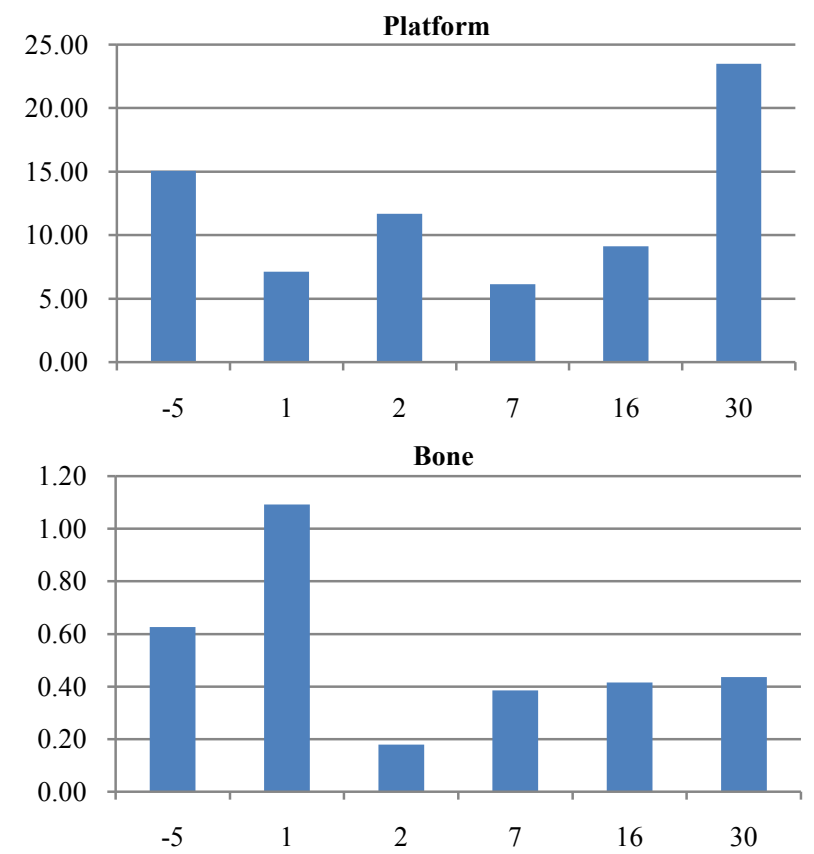

Figure 1. Use of platform and bone (\% of observation time). -5 is five days before transferring animals from their home cages to multi-enriched cages. 1, 2, 7, and 16 are days in multi-enriched cages. Foxes were 26 days in multi-enriched cages. 30 is four days since foxes had been transferred back to home cages. 


\subsection{Behavioural Changes}

Locomotor activity, sitting and standing varied with time $(\mathrm{P}<0.05)$. Lowest values for locomotor activity and sitting were found when foxes were in multi-enriched cages (Days 2 and 7). The amount of standing was low in Days 2, 7 and 16. The amount of lying did vary with time (Figure 2).

The amount of stereotypy varied between recording days $(P<0.05$; Figure 3$)$. When foxes were transferred from home cage to multi-enriched cages, no change was found in the amount stereotypy during Days 1 and 2. Thereafter, the amount of stereotypy tended to declined, being lowest on Day 16. The amount of stereotypy tended to increase when foxes were transferred back to home cages (Day 30).

\subsection{Behavioural Test Reactions}

Explorativity markedly increased $(\mathrm{P}<0.05)$ when animals were transferred from their home cages to enriched cages (Figure 4). Explorativity remained high during entire study period when foxes were kept in enriched enrichment. Furthermore, it remained high also after transferring of animals back to home cages. Capture reaction was quite similar in home and enriched cages (Figure 3).

\section{Discussion}

Environmental enrichment can be considered as the addition of environmental features that enhance the complexity of the captive animal's environment, resulting in beneficial effect on behaviour and other aspects of biological function [1] [8]. In the present study, traditional cage with platform and gnawing object was furnished with 6 additional enrichments. Several approaches were used here to evaluate possible beneficial effects of available enrichments. The basic idea of the multi-enriched cages for farmed blue foxes was here to provide the animals with opportunities to fulfil various behavioural motivations, and hence stimulate the animals both physically and mentally. For example, the platform and top nest box were expected to serve as places for resting and observation and encourage vertical movement, whereas the activity EEs stimulate particularly exploration and play but also scratching, chewing, pulling and ripping [15].
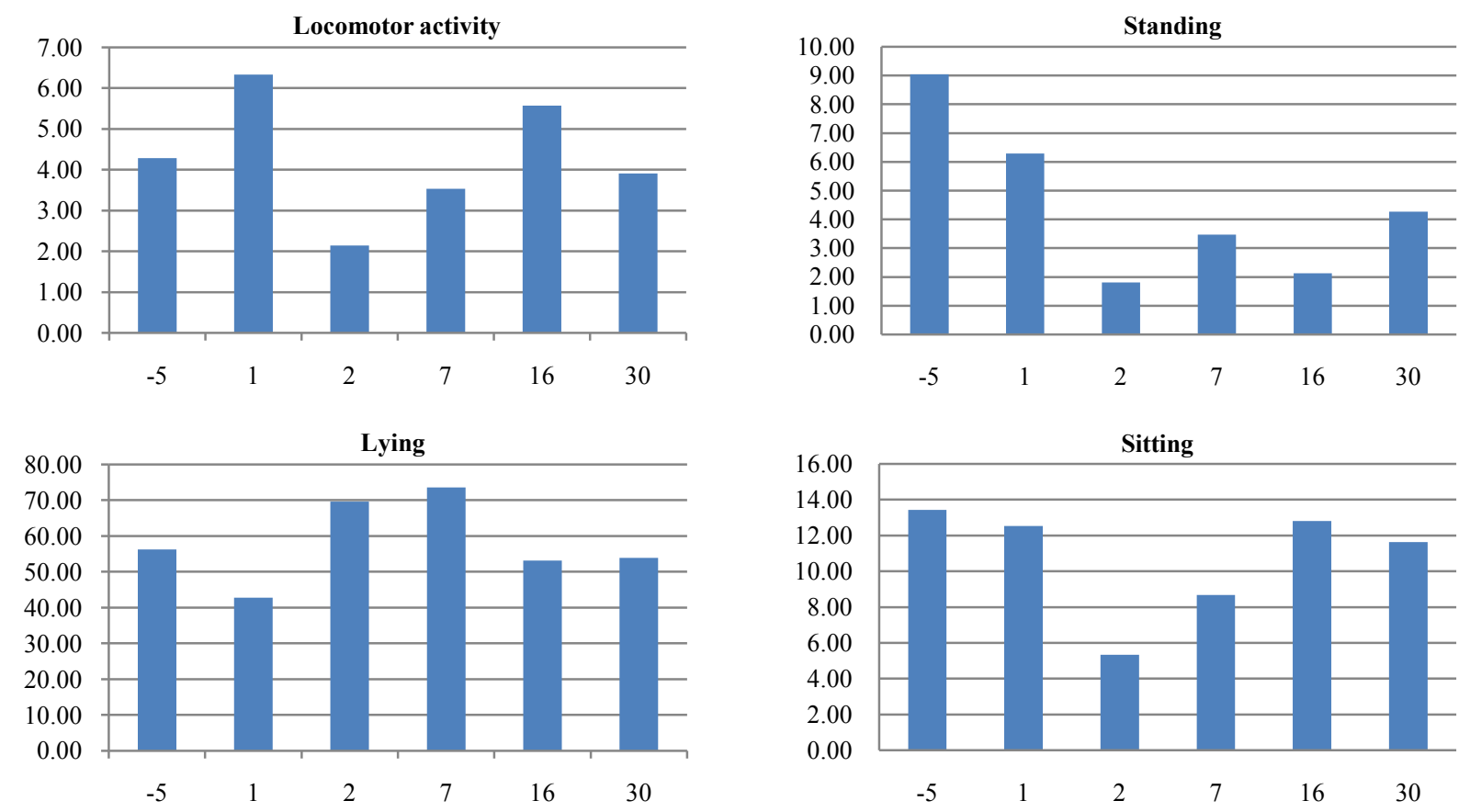

Figure 2. Locomotor activity, and sitting, lying and standing behaviour ( $\%$ of observation time) during the course of the study. -5 is five days before transferring animals from their home cages to multi-enriched cages. 1, 2, 7, and 16 are days in multi-enriched cages. Foxes were 26 days in multi-enriched cages. 30 is four days since foxes had been transferred back to home cages. 


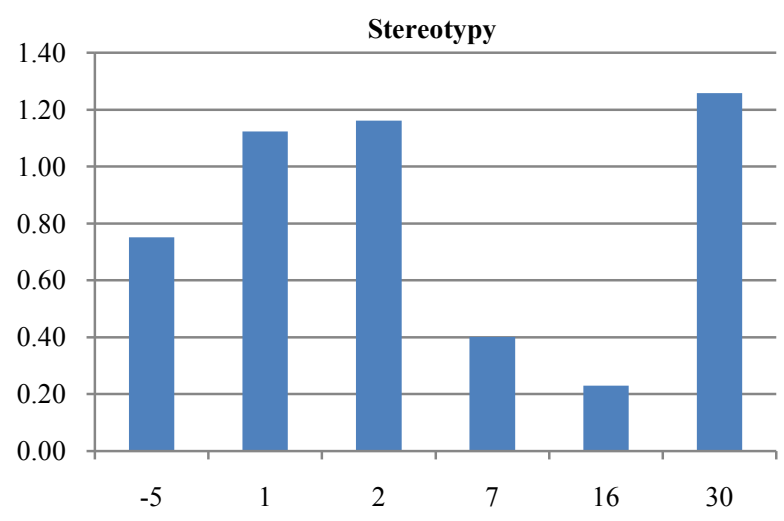

Figure 3. The amount of stereotypy ( $\%$ of observation time). -5 is five days before transferring animals from their home cages to multi-enriched cages. $1,2,7$, and 16 are days in multi-enriched cages. Foxes were 26 days in multi-enriched cages. 30 is four days since foxes had been transferred back to home cages.

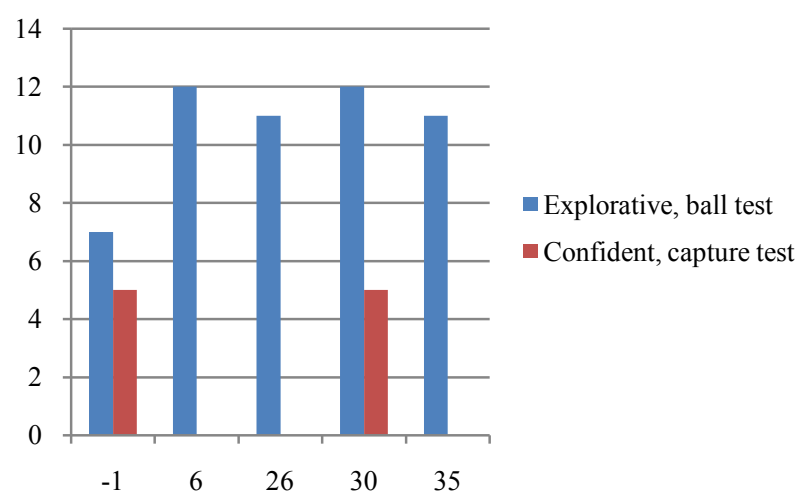

Figure 4. The amount of explorative and confident foxes (as number of animals) at ball and capture tests. -1 is one day before transferring animals into the multi-enrichd cages. 6 and 26 are days in multi-enriched cages. 30 and 35 are four and nine days since foxes were transferred back into their home cages.

Housing systems promoting exploration can be expected to improve animal welfare, or, conversely, conditions which do not encourage animals to behave exploratively often tend to be unfavourable also in terms of animal welfare [18] [19]. Our present results clearly showed that explorativity markedly increased when animals were transferred into the multi-enriched cages. Explorativity remained high during entire study period when foxes were kept in enriched enrichment. Furthermore, it remained high also after transferring of animals back to home cages. This indicates that enriched environment increases foxes' explorativity and, thus, enhances animal welfare. The number of confident foxes was same both in home and enriched cages. This tends us to conclude that increase of enrichments in the cage do not promote animal's confident to human being.

The decrease in the use of the EEs most probably reflects the novelty effect that they had immediately after being provided to the foxes [15]. This effect was not as clear for the platform, top nest box and wall rope as for the other EEs. The foxes had had platforms in their home cages before the experiment, and therefore, they were familiar with the platforms, which may have resulted in the rather steady day-to-day use of the platform as measured by the time spent on the platform. The more frequent visits to the platform on Day 1 than later could be explained by the need to patrol the new cage, including the top nest box that could be entered only via the platform. The preference for the wall rope was clearest on Days 2, 7 and 16, and the longer lasting interest towards the wall rope than other "activity EEs" might be (at least) partially explained by the novelty brought with 
the renewed ropes.

The durability of the sisal ropes was very poor, and in future studies alternatives for sisal has to be considered. There were no durability problems with any other EEs. However, the study period was too short to indicate any other than acute durability problems. The present results indicate that our adult blue foxes used these opportunities diversely.

The amount of stereotypic behaviour typically is a clear indicator of animal welfare. In farmed foxes, the amount of stereotypy typically is not high [19]. Also in the present study the amount of stereotypy was rather low in general. Thus, it is difficult to make any far-reaching conclusions on the effects of enrichments on stereotypy. However, some variation with time and/or cage furnished was evident. Lowest amount of stereotypy was found on Days 7 and 16 at multi-enriched cages. Furthermore, amount of stereotypy was highest after transferring foxes back to home cages. These changes, although not significant, temps us to conclude that the amount of stereotypy may be lower in multi-enriched that in more barren environment. This finding requires further studies.

Platform and bone were the only enrichments what were available for foxes during the entire study. It was seen that platform was used mostly when foxes were at their home cage, i.e. in situation when other enrichments except bone were not available. So, it looks that foxes compensate lack of enrichments by increased use of platform. Use of gnawing bone, on the other hand, seems to be low despite of enrichments available. According to the present results enrichment value of bone is low compared to platform. Behavioural data did not reveal any dramatic differences between home and enriched cages. Particularly lying on cage floor remained rather similar throughout the study.

\section{Conclusion}

For most studied enrichments both the time spent in contact and the frequency of contacts with the enrichments declined steeply after Day 1, reflecting a novelty effect of enrichments. This decline was not so evident for the platform, top nest box and wall rope. Multi-enriched environment increased foxes' explorativity, and thus probably enhanced animal welfare. Our results indicated that the blue foxes used readily the opportunities for more diverse behaviour in a multi-enriched environment.

\section{Acknowledgements}

This study was financially supported by the Finnish Fur Breeders’ Association.

\section{References}

[1] Van de Weerd, H.A. and Day, J.E.L. (2009) A Review of Environmental Enrichment for Pigs Housed in Intensive Housing System. Applied Animal Behaviour Science, 116, 1-20. http://dx.doi.org/10.1016/j.applanim.2008.08.001

[2] Bauman, V. and Van Loo, P.L.P. (2013) How to Improve Housing Conditions of Laboratory Animals: The Possibilities of Environmental Refinement. Veterinary Journal, 195, 24-32. http://dx.doi.org/10.1016/j.tvj1.2012.09.023

[3] Valtioneuvosto (2011) Valtioneuvoston asetus turkiseläinten suojelusta 1084/2011. Helsinki 20.10. 2011.

[4] Koistinen, T. and Korhonen, H.T. (2013) Complex Housing Environment for Farmed Blue Foxes (Vulpes lagopus): Use of Various Resources. Animal, 7, 1354-1361. http://dx.doi.org/10.1017/S1751731113000402

[5] Korhonen, H. and Niemelä, P. (1999) Enrichment Value of Wooden Blocks for Farmed Blue Foxes (Alopex lagopus). Animal Welfare, 9, 177-191.

[6] Koistinen T. (2009) Farmed Blue Foxes' (Vulpes lagopus) Need for a Sand Floor. Kuopion yliopiston julkaisuja C. Luonnontieteet ja ympäristötieteet 259. Kopijyvä, Kuopio.

[7] Korhonen, H. and Huuki, H. (2011) Digging and Its Welfare Implications for Farmed Blue Fox. Annals of Animal Science, 11, 293-305.

[8] Korhonen, H.T., Jauhiainen, L. and Niemelä, P. (2002) Wooden Blocks and Straw as Environmental Enrichments for Juvenile Blue Foxes (Alopex lagopus). Acta Ethologica, 5, 29-37. http://dx.doi.org/10.1007/s10211-002-0067-0

[9] Koistinen, T., Jauhiainen, L. and Korhonen, H. (2009) Relative Value of a Nest Box, Sand Floor and Extra Space during the Breeding Season in Adult Blue Fox Males. Applied Animal Behaviour Science, 120, 192-200. http://dx.doi.org/10.1016/j.applanim.2009.07.004

[10] Hansen, S.W., Malmkvist, J., Palme, R. and Damgaard, B.M. (2007) Do Double Cages and Access to Occupational 
Materials Improve the Welfare of Farmed Mink? Animal Welfare, 16, 63-76.

[11] Meagher, R.K. (2011) The Welfare Significance of Inactivity in Captive Animals, Using Mink as a Model. Ph.D. Thesis, Guelph, Ontario.

[12] Mason, G.J., Haley, D. and Dawson, L. (2012) Simple Year-Round Cage Enrichments for Mink. Scientifur, $36,491$.

[13] Mason, G.J., Bahlmann, K., Dawson, L., Ahloy Dallaire, J., Meagher, P.K., Bowyer, S., Diaz-Leon, M. and Campbell, D. (2012) Elevated Resting Bunks for Nursing Mink Dams. Scientifur, 36, 492.

[14] Newberry, R.C. (1995) Environmental Enrichment: Increasing the Biological Relevance of Captive Environments. Applied Animal Behaviour Science, 44, 229-243. http://dx.doi.org/10.1016/0168-1591(95)00616-Z

[15] Frondelius, L., Korhonen, H.T., Huuki, H. and Mononen, J. (2013) Multi-Enriched Cage Environment for Farmed Blue Foxes: The Extent of the Use of the Various Enrichments. NJF Seminar 464, 28 -30 August 2013, Reykjavik, 8.

[16] Korhonen, H.T. and Orjala, H. (2010) Effect of Cage Dimensions on Welfare and Production of Farmed Blue Fox. Annals of Animal Science, 10, 311-324.

[17] SAS Institute, Inc. (1999) SAS/STAT® User's Guide. Version 8, SAS Institute Inc., Cary, 3809.

[18] Mononen, J. (1998) Evaluation of the Open Field Test. Proceedings of the Nordic ISAE Winter Meeting, Tune, 28-30 January 1998, 6.

[19] Korhonen, H.T., Jauhiainen, L. and Rekilä, T. (2006) Effects of Year-Round Nestbox Availability and Temperament on Welfare and Production in Blue Foxes (Alopex lagopus). Annals of Animal Science, 6, 149-167. 